\title{
La administración pública en la Monarquía de los Austrias y en el Reino de Hungría en los siglos XVI-XVII
}

\section{Public Administration in the Habsburg Monarchy and the Kingdom of Hungary in the $16-17^{\text {th }}$ century}

\author{
András OROSS \\ Archivero delegado \\ Delegación del Archivo Nacional de Hungría \\ Österreichisches Staatsarchiv, Haus-, Hof- und Staatsarchiv, \\ Wien \\ ung.archdel@gmail.com \\ Tibor MARTÍ \\ Investigador \\ Instituto de Historia del Centro de Investigaciones de Humanidades \\ de la Academia de Ciencias de Hungría \\ Departamento de Historia Moderna \\ Budapest \\ marti.tibor@btk.mta.hu
}

Recibido: 31 de octubre de 2014

Aceptado: 18 de diciembre de 2014

\section{RESUMEN}

El objetivo del presente estudio es dar un panorama general sobre la Monarquía de los Austrias en la temprana Edad Moderna, y del reino de Hungría en los siglos XVI-XVII, en una situación legal y administrativa muy peculiar y diferente de otros territorios de la monarquía. En el artículo se presentan: los órganos gubernamentales fundamentales en la gestión de la monarquía compuesta (el soberano; los Consejos ante el soberano; la Cancillería de la Corte; la Cámara de la Corte; y el Consejo de Guerra Áulico); las oficinas más importantes del estado húngaro dividido en tres partes (1. la administración nobiliario real de Hungría: el consejo de Hungría, el lugarteniente, el palatino y la Asamblea Nacional, 2. la Cancillería Real de Hungría, 3. el sistema de las cámaras para gestionar las finanzas de Hungría); y la provincia, escenario principal de la administración a nivel intermedio y la garantía del autogobierno de la nobleza. El estudio detalla también las condiciones gobernativas y administrativas del Reino de Croacia y de Eslavonia, ambos en unión personal con el reino de Hungría desde 1102, y el desarrollo autónomo del sistema político de Transilvania, además da a conocer -a través del ejemplo de las ciu-

\footnotetext{
${ }^{1}$ Los autores dan las gracias al licenciado Ádám András Kürthy y a la doctora Mónika Edina Bán por la traducción del texto, por la revisión al doctor Roberto Quirós Rosado. El mapa de Hungría dividida en tres partes (siglos XVI-XVII) ha sido dibujado por Béla Nagy (Instituto de Historia del Centro de Investigaciones de Humanidades de la Academia de Ciencias de Hungría, Budapest).
} 
dades reales libres-el sistema administrativo urbano, y -para terminar- extiende su mirada hacia el período posterior a la ocupación otomana.

PALABRAS CLAVE: Reino de Hungría, administración pública y órganos ministeriales en la época moderna, Monarquía de los Habsburgo, la rama austriaca de la Casa de Austria, sistema de gobierno.

\begin{abstract}
The fundamental aim of the present paper is to provide an overview of the public administration of early modern Habsburg Monarchy and the Kingdom of Hungary, distinguished from the other countries and provinces of the Monarchy by its own historical constitution and characteristically different system of government, in the 16-17th century. The article describes the governing authorities playing a central role in the administration of the Monarchy as a diverse and complex ("composite monarchy") political entity (the sovereign, the imperial and royal councils, the Court Chancellery, the Court Chamber and the Court Council of War) as well as the major government offices of the Hungarian state split into three parts: 1. the royal authorities and the government offices of the Hungarian estates: the Hungarian Council, the governor, the palatine, the parliament, 2. the Hungarian Royal Court Chancellery, 3. the chamber system managing the finances of the Kingdom of Hungary, furthermore the overriding scene of middletier administration and the paramount factor of noble autonomy: the county. The paper also discusses the government and public administration of the Kingdom of Croatia, united with Hungary since 1102 in the form of a personal union, and the distinctive development of Transylvania's organization of state as well as it depicts, by referring to the example of the royal free cities, contemporary town administration and provides a brief survey of the aftermath of the Ottoman conquest.
\end{abstract}

KEYWORDS: Kingdom of Hungary, public administration and government organizations in the Early Modern Period, Habsburg Monarchy, the Austrian line of the House of Habsburg, administration/government, history.

\title{
RÉSUMÉ
}

L'objectif de la présente étude est d'offrir un vaste tableau de l'administration du Royaume de Hongrie aux XVI ${ }^{\mathrm{e}}$-XVIII ${ }^{\mathrm{e}}$ siècles, ayant une constitution autonome des ordres à l'intérieur de la Monarchie des Habsbourg qui différait particulièrement dans le domaine juridique et administratif des autres territoires de la Monarchie. Dans l'étude, il s'agit de la présentation des différents organes ayant une importance centrale dans l'organisation de la monarchie composite et multiple (le souverain ; conseils auprès du souverain ; la Chancellerie aulique et la Chambre aulique, ainsi que le Conseil aulique de guerre) et les institutions les plus importantes de l'État hongrois déchiré en trois parties : 1) les institutions des ordres et du roi : le conseil hongrois, le lieutenant, le palatin, la diète, 2) la Chancellerie aulique royale hongroise, 3) le système caméral dirigeant les finances du Royaume de Hongrie, ainsi que le lieu de l'administration à niveau moyen et l'institution de l'auto-administration nobiliaire : le comitat. L'étude s'occupe également des circonstances du gouvernement et de l'administration du Royaume de Croatie liée au Royaume de Hongrie par une union personnelle depuis 1102 et de la Slavonie au cours des $\mathrm{XVI}^{\mathrm{e}}-\mathrm{XVII}^{\mathrm{e}}$ siècles, du développement de l'organisation étatique de la Transylvanie. Elle présente également l'administration des villes par l'exemple des villes royales libres, ce qui donne une vue sur la situation du pays après l'occupation ottomane.

MOTS CLÉ : Royaume de la Hongrie, administration publique et organes ministériels dans l'époque moderne, la Monarchie des Habsbourg, la branche Autrichienne de la Maison de l'Autriche, système de gouvernement.

\section{ZUSAMMENFASSUNG}

Das grundlegende Ziel der Studie ist, die öffentliche Verwaltung der frühneuzeitlichen Habsburgermonarchie und des Königtums Ungarn - das über eine selbständige ständische Verfassung verfügte und 
hinsichtlich des öffentlichen Rechtes sowie seines Regierungssystems von den anderen Gebieten der Monarchie eigenartig abwich - im 16-17. Jahrhundert umfassend darzustellen. Im Artikel werden die in der Administration der vielfältigen komplexen Monarchie (monarquía compuesta) eine zentrale Rolle spielenden Regierungsorgane (der König; die Räte neben dem König; die Hofkanzlei und die Hofkammer, sowie der Hofkriegsrat) und die wichtigsten Ämter des dreigeteilten ungarischen Staates vorgestellt: 1. die ungarischen ständischen und königlichen Ämter: der Ungarische Rat, der Statthalter, der Palatin, der Landtag, 2. die Ungarische Königliche Hofkanzlei, 3. das Kammersystem, das die finanziellen Angelegenheiten des Königtums Ungarn lenkte, weiterhin der wichtigste Schauplatz der Verwaltung mittlerer Ebene und der Schlüsselfaktor der adeligen Selbstverwaltung: das Komitat. Die Studie befasst sich auch mit den Verhältnissen der Regierung und der öffentlichen Verwaltung des Königtums Kroatien und Slawonien (das seit 1102 mit dem Königtum Ungarn eine Personalunion bildete) im 16-17. Jahrhundert, weiterhin mit der separaten Entwicklung der staatlichen Organisation von Siebenbürgen, schildert zugleich durch das Beispiel der königlichen freien Städte die städtische Verwaltung und gewährt auch einen kurzen Überblick über die Epoche nach der osmanischen Eroberung.

SCHLÜSSELWÖRTER: Königreich Ungarn, Verwaltungssystem und Regierungsorganisation in der Frühen Neuzeit, mitteleuropäische zusammengesetzte Habsburgermonarchie, österreichische Linie der Habsburgerdynastie, Verwaltungsgeschichte.

SUMARIO: 1. Soberano por la gracia de Dios. 2. La administración central vienesa. El escenario más estricto de las decisiones: los consejeros ante el soberano. 3. Dirección política y de los asuntos exteriores: la Cancillería de la Corte. 4. Dinero, dinero, dinero... y aún más dinero: la Cámara de la Corte. 5. La dirección militar y su lenta centralización: el Consejo de Guerra Áulico. 6. Los oficios reales y de los Estados húngaros. 6.1. Los escenarios húngaros de los preparativos y de la toma de decisiones: el Consejo Húngaro, el lugarteniente, el palatino y la Asamblea Legislativa. 6.2. Gestión política y jurisdicción: la Cancillería Real Húngara de la Corte. 6.3. Los asuntos financieros del Reino Húngaro: el sistema de la Cámara. 6.4. El escenario de la administración pública de nivel intermedio y el de la autonomía de la nobleza: la provincia. 6.5. Gobierno y organización interna de las ciudades del reino de Hungría: el ejemplo de las ciudades reales libres. 6.6. Croacia y Eslavonia. 6.7. Los «caminos separados» de Transilvania. 6.8. Una mirada al período postotomano: el gobierno de Hungría em los siglos XVIIIXIX: el Consejo de Lugartenencia. Bibliografía selecta.

Fernando I (1526-1564), monarca de la Casa de Austria, coronado rey de Hungría después de la batalla de Mohács, efectuó varias reformas administrativas en su Imperio en continua expansión, las cuales hicieron sentir su efecto en la vida política a lo largo de varias décadas. Las innovaciones en el terreno de la dirección pública, financiera y militar, introducidas hasta mediados del siglo XVI afectaron a toda la Monarquía de la Casa de Austria, y dentro de ella, naturalmente, al Reino de Hungría. ${ }^{2}$ Esta época se corresponde con el periodo de la formación de lo que se considera la administración moderna y profesional, de la cual son rasgos distintivos la separación

\footnotetext{
${ }^{2}$ István Fazekas, „Die Habsburger und Ungarn im 16. Jahrhundert”, Kaiser und König. Eine historische Reise. Österreich und Ungarn 1526-1918, Coord. y descripciones de los objetos de la exposición: István Fazekas y Gábor Ujváry. Viena, 2001, 33. Géza Pálffy, The Kingdom of Hungary and the Hasburg Monarchy in the Sixteenth Century, Boulder, Colorado, Social Science Monographs-Wayne, New Jersey, Center for Hungarian Studies and Publications, Inc.-New York, 2009, 53-70.
} 
exacta de las competencias, el funcionamiento continuo y la gestión colegial. En contraste con las condiciones medievales, el objetivo principal fue lograr la separación de las grandes ramas de la vida administrativa tanto en el nivel personal como en el de la división de los oficios. En el caso de los ministros, se planteó en primer plano la pericia y el conocimiento profundo de la competencias asignadas; también, participaron en la elaboración de las disposiciones soberanas. Para ayudar a la toma de decisiones, al lado del príncipe seguía funcionando un grupo estrecho de consejeros, los cuales formaban parte del gremio debido a su alto cargo eclesiástico o regio. ${ }^{3} \mathrm{Sin}$ embargo, a la aristocracia húngara les parecía legalmente harto problemática la introducción de las medidas que tenían como fin el establecimiento del nuevo sistema político en Hungría. ${ }^{4}$ El objetivo de los nobles era mantener independientes las nuevas oficinas reales de Hungría de la administración central, vienés en su mayoría, y lograr que solo el soberano estuviera sobre ellos. Dado que el rey de Hungría era también soberano de otros territorios, en los asuntos de Hungría escuchaba también a los consejeros en los que se apoyaba para gobernar todo el Imperio. Las guerras cada vez más continuadas contra el Imperio otomano en los siglos XVI-XVII -si se quierese convirtieron en asunto de todo el Imperio, en el cual estaban interesados no solo la nobleza húngara y austríaca, sino también las provincias de la Corona de Bohemia y el Sacro Imperio Romano.

\section{Soberano por la gracia de Dios}

En el siglo XVI, el territorio gobernado por la Casa de Austria creció sin cesar, especialmente en la parte oriental de Europa. Además de las posesiones familiares de los Habsburgo, estaban bajo su administración las Provincias Hereditarias (Austria Inferior, Austria Superior y Austria Interior), los países de la Corona de Bohemia (Bohemia, Moravia, Silesia y Lusacia) a partir de 1526, y los países de la Corona del rey San Esteban (el reino de Hungría, Eslavonia, Croacia y Dalmacia) a partir de 1527. Tras la abdicación de Carlos V, emperador del Imperio Romano Germánico (Sacro Imperio Romano) (1519-1556), Fernando I obtuvo el título de emperador, de manera que el gobierno del Imperio Romano Germánico (Sacro Imperio Romano) pasó a las manos de la rama austríaca de la familia de los Habsburgo.

Para una mejor comprensión, he aquí los títulos llevados por Leopoldo I (rey de Hungría entre 1657-1705), utilizados al firmar la Paz de Karlowitz (1699): "Leopoldum, electum Romaniorum Imperatorem, semper Augustum Germaniae, Hungariae,

\footnotetext{
${ }^{3}$ Stefan Sienell, „Die Protokolle zentralstaatlicher politischer Ratskollegien (1527-1742/60)”, Quellenkunde der Habsburgermonarchie (16-18. Jahrhundert). Ein exemplarisches Handbuch, Oldenbourg, Wien-München, 2004, 120-127. (MIÖG, Bd. 44). Para el siglo XVII: Henry Frederick Schwarz, The Imperial Privy Council in the Seventeenth Century, Coddington, Cambridge 1943.

${ }^{4}$ Kálmán Benda, Habsburg-abszolutizmus és rendi ellenállás a XVI-XVII. században [Absolutismo de los Habsburgo y oposición de la nobleza húngara en los siglos XVI-XVII], Budapest, 1975.
} 
Bohemiae, Dalmatiae, Croatiae, Sclavoniae Regem, Archiducem Austriae, Ducem Burgundiae, Brabantiae, Styriae, Carinthiae, Carniolae, Marchinem Moraviae, Ducem Luxemburgiae, Superioris et Inferioris Silesiae, Wirtembergae et Teckae, Principem Sveciae, Comitem Hapspurgi, Tyrolis, Kyburgi et Goritiae, Marchionem Sacri Romani Imperii, Burgoviae ac Superioris et Inferioris Lusatiae, Dominum Marchiae Schlavoniae, Portuus Naonis et Salinarum ab una". Este estado, unificado por la persona del soberano, fue una monarquía compuesta -una construcción común en la Europa de la época-, cuyos países fueron similarmente compuestos, o sea podían estar constituidos por varias provincias.

Uno de los derechos más importantes y más ancestrales de la nobleza húngara había sido el del libre sufragio para elegir el monarca, que se vio agraviado en varios aspectos entre los siglos XVI-XVIII. En diciembre de 1526 eligieron rey de Hungría a Fernando de Habsburgo, pero la nobleza húngara no reconoció el derecho de la dinastía a la pretensión al trono hasta el artículo $\mathrm{V}$ del año 1547 , pero en éste tampoco se mencionó la coronación automática del archiduque primogénito. Hasta finales del siglo XVII, la nobleza húngara -en contraste con la austríaca y la bohemia- pudo ejercer parcialmente su sufragio. Esto tuvo importancia especial cuando el rey no tenía descendiente masculino, tal como lo demuestran ejemplarmente los acontecimientos de 1608, cuando Rodolfo (1576-1608) "traspasó" el reino de Hungría a su hermano Matías (1608-1619). En la Asamblea Nacional de 1687, la nobleza -guiada por la gratitud hacia la dinastía tras la expulsión de los otomanos, y por la intercesión eficaz del palatino Pál Esterházy- reconoció la sucesión de las ramas austríaca e hispánica de la Casa de Austria, e incluso aprobaron la derogación de la cláusula de resistencia, establecida en la Bula de Oro, puesta en efecto por el rey húngaro András II con el artículo XXXI del año 1222. Dado que no tuvieron hijos varones ni José I (rey de Hungría entre 1705-1711), ni su hermano y sucesor Carlos III (o VI, 1711-1740), en algunas provincias de la Monarquía se iniciaron negociaciones con la nobleza para que se aprobara la sucesión femenina. En 1712 la Asamblea de la nobleza de Croacia, en 1722 la de Transilvania y en 1723 la de Hungría aceptaron no sólo la sucesión femenina, sino también la alianza perpetua e indivisible de todos los países y futuras adquisiciones de la Casa de Austria para una mayor seguridad y para la mutua defensa, y convinieron en que el sufragio volviera a entrar en vigor exclusivamente en el caso de la extinción completa de la dinastía.

En el conjunto de los estados de la Monarquía de los Austrias -tal como acabamos de ver-, el soberano estaba autorizado a gobernar bajo varios títulos. Ejerció su poder ejecutivo a través de órganos directivos centrales y territoriales, y en la toma de de-

\footnotetext{
${ }^{5}$ A karlócai béke és Európa: dokumentumok a karlócai béke történetéhez, 1698-1699 [La Paz de Karlowitz y Europa: documentos sobre la historia de la paz de Karlowitz, 1698-1699], Coord. Szita László et al., Pécs, 1999, p. 213, n 53. Sobre la titulación de los Habsburgo: Pálffy, The Kingdom of Hungary..., 2009, p. 59 y „,Figure 2”.
} 
cisiones le ayudó la administración diversificada de sus países y provincias. La administración central establecida hasta mediados del siglo XVI en la capital de la monarquía tenía autoridad sobre cada provincia de todos los países gobernados por la rama austríaca de los Habsburgo; hay que tener en cuenta, sin embargo, que el soberano tenía influencia casi absoluta sobre los asuntos exteriores, militares y financieros. Los órganos gubernamentales redactaron juicios, disposiciones y órdenes bajo su nombre, fue él quien negociaba y firmaba convenios con los demás soberanos de Europa, y fue él el jefe militar supremo. Tenía poder exclusivo también en el terreno de la justicia como juez principal; dictaba leyes cooperando tradicionalmente con la Asamblea de la nobleza, pero éstas se promulgaban sólo habiendo obtenido su beneplácito. En la legislación hacía prevalecer su derecho a decretar, así que quedaba en su poder establecer principios legales sin el consentimiento de la nobleza.

De aquí en adelante detallaremos los órganos gubernamentales y los ministros adjuntos que ayudaron al rey a la hora de tomar decisiones. Puesto que los asuntos de cada país a veces se convirtieron en asuntos fundamentales para toda la Monarquía, resulta difícil separar los órganos a los cuales el reino de Hungría les concernía exclusivamente. Por ejemplo, el sistema de fortalezas contra los otomanos y la manutención del ejército estacionado en Hungría se consideraron como un asunto imperial, en que el soberano escuchó no sólo el parecer de los húngaros, sino también el de los oficiales de los órganos gubernamentales.

\section{La administración central vienesa. El escenario más estricto de las deci- siones: los consejeros ante el soberano}

Las características más importantes de la nueva administración, establecida entre finales del siglo XV e inicios del siglo XVI fueron la consistencia, la centralización y el sistema colegial, las cuales en la época pueden ser consideradas como fundamentos de la moderna administración pública. Los foros de consejeros, en cambio, no participaron en la elaboración de decisiones, sino que ayudaban al soberano en el acto mismo de las disposiciones y lo hacían bajo nombres diferentes (p. ej.: Consejo Áulico, Conferencia Secreta), pero con funciones más o menos constantes. Estos foros, a diferencia de los medievales, tenían su lugar en la corte real, y participaban con cada vez más frecuencia en las sesiones convocadas para discutir asuntos específicos. El trabajo de los consejeros fue necesario también para que facilitaran la decisión del monarca en los asuntos específicos; comprensiblemente, la mayoría de ellos fueron ministros principales de la corte, complementados por los representantes administrativos de mayor relieve y por otros miembros invitados.

El Consejo Áulico (Hofrat), establecido a comienzos del siglo XVI, participó sobre todo en las disposiciones políticas, legislativas y diplomáticas del soberano, pero también tenía un papel importante en la jurisdicción. Sin embargo, a partir de la segunda mitad del siglo XVI, los emperadores Habsburgo prefirieron hacerse acon- 
sejar por el Consejo Secreto (Geheimer Rat) en el caso de asuntos más confidenciales. Hasta el siglo XVII, no obstante, se habían otorgado tantos títulos de consejero secreto, que la convocatoria de los consejeros supuso un problema cada vez más grave, de modo que la función de este Consejo se redujo a la inanidad; y en los tiempos de Leopoldo I empezó a divisarse la institución de la Conferencia Secreta (Geheimer Conferenz), que estaba compuesto de miembros fijos, pero fue convocada exclusivamente para discutir casos específicos y concretos. En estas conferencias participaban oficiales de alto cargo de la Corte y de la administración; se trataba sobre los asuntos propuestos, y se proponían recomendaciones para el soberano.

Para tratar algunos asuntos de importancia destacada-como aquellos relacionados a lo acontecido en Hungría en la segunda mitad del siglo XVII, la organización del reino de Hungría, reconquistado de los otomanos- se establecieron comisiones especializadas dentro de la Conferencia Secreta, las cuales, complementadas con miembros invitados, formulaban su dictamen para el soberano. Por lo tanto, no es posible dar una lista consistente y regular de los participantes de estos foros decisorios, puesto que fueron diferentes en cada sesión. Para tener un ejemplo, veamos la Comisión Áulico Principal para la reorganización de Hungría: el presidente fue Ferdinand Dietrichstein, Mayordomo principal de la Corte, es decir, uno de las figuras más ilustres y destacadas de la Corte de los Habsburgos de Austria, y los miembros fueron Franz Ulrich Kinsky (Canciller principal de Bohemia), Wolfgang Andreas Orsini von Rosenberg (Presidente de la Cámara de la Corte) y Ernst Rüdiger Starhemberg (Presidente del Consejo de Guerra Áulico). En el trabajo de la subcomisión, designada por Dietrichstein, bajo la presidencia del obispo de Győr, Lipót Kollonich, tomaron parte Franz Joseph Krapf (Secretario del Consejo de Guerra Áulico), Christoph Siegfried Breuner (Vicepresidente de la Cámara de la Corte), Friedrich Julius Buccellini (Vicecanciller de la Corte), Johann Georg Hoffmann (consejero del Gobierno de Austria Inferior) y Carl Gottlieb Aichpichl (consejero de la Cámara de la Corte).

Los escribanos de la Cancillería prepararon notas sobre cada sesión del Consejo Secreto y los secretarios redactaron los textos de los decretos bajo la inspección del director de la Cancillería de la Corte (Hofkanzlei, Cancellaria Aulica), según la decisión del soberano; y, recibido el visto bueno, los escribanos redactaron las copias detalladas. Por tanto, la Cancillería mantuvo relaciones estrechas con los consejos más estrictos desde el primer momento. En el caso de la Conferencia Secreta, sin embargo, las comisiones emplearon secretarios y escribanos de la Cámara o del Consejo de Guerra, por lo que el papel de ellos también experimentó un aumento notable.

\section{Dirección política y de los asuntos exteriores: la Cancillería de la Corte}

A partir de la Alta Edad Media, la función más importante de la Cancillería de cada soberano fue realizar la redacción, las copias detalladas y la edición de los decretos reales. Los secretarios de la Cancillería -dada su presencia en varios consejos y esce- 
narios decisorios del soberano-desempeñaban cargos prominentes. También asumían con frecuencia el trabajo de los consejeros áulicos y secretos, así que en realidad tenían influencia sobresaliente en los asuntos particulares. Puede afirmarse en general que el rasgo más fundamental de cada Cancillería fue su continua presencia ante el soberano; por tanto, en una Corte - como la de Viena-donde se reunían representantes de todos los países y provincias del monarca Habsburgo, residían también varias cancillerías. A mediados del siglo XVI, Fernando I se había apropiadao de la soberanía de muchos países, por eso podía parecer lógica la voluntad de centralizar, para que todo el Imperio tuviera una única Cancillería. Finalmente, las cancillerías de los países adquiridos a comienzos del siglo XVI no se fundieron completamente en la temprana Edad Moderna, sino en menor o mayor grado conservaron su autonomía.

La Cancillería del Imperio Romano Germánico, la encabezaba tradicionalmente el arzobispo de Mainz, y debajo de él actuaba un vicecanciller, cuya influencia inmediata a las decisiones era mayor que la del Canciller, puesto que participaba en el consejo secreto del soberano como miembro regular. El primero en intentar la utilización de su Cancillería Áulica -responsable de los asuntos de las provincias austríacas- como Cancillería Imperial a la vez fue el emperador Maximiliano I (1508-1519); la unificación se demoraría hasta 1558-1559, cuando Fernando I subió al trono imperial. Al Vicecanciller Imperial se le otorgó también el título de Canciller de Austria, aunque se prestó atención especial a que los asuntos de los dos territorios no se mezclaran, tal como se puso de relieve con la administración separada. Además de la redacción de actas y del manejo de la correspondencia diplomática, correspondió a este órgano la custodia del sello imperial y vigilar el funcionamiento del Archivo. En 1620 se produjo otra reforma: la Cancillería Austríaca se separó de la Imperial y de allí en adelante funcionó como órgano autónomo. En la misma década, se reformó también la Cancillería de Bohemia: se le asignó la función jurisdiccional, ya que al mismo tiempo ejercía como Tribunal Supremo del país. La función tradicional de la Cancillería Imperial fue manejar la correspondencia diplomática, y -a través de ella- los asuntos exteriores; logró conservar esta función hasta finales del siglo XVIII.

\section{Dinero, dinero, dinero... y aún más dinero: la Cámara de la Corte}

Para el manejo unificado de las finanzas de los territorios bajo su dominio, Fernando I estableció la Cámara de la Corte (Hofkammer, Camera Aulica) en 1527, a la que seguirían en poco tiempo la Cámara de Bohemia (1527), la Cámara de Hungría (1528) y los órganos de dirección financiera de cada Provincia Hereditaria. ${ }^{6}$ La coordinación centralizada de las finanzas propició que los ingresos procedentes de diversos países y provincias fueran manejados por una administración especializada, constituida por un grupo de oficiales profesionales. Al establecer la Cámara, Fernando

${ }^{6}$ „Die Hofkammer”, Quellenkunde..., 2004, 128-161. 
se propuso, por una parte, designar como dirigentes financieros a personajes independientes de la nobleza y, por otra, dirigir las finanzas de su Imperio mediante un órgano consiliario profesional de forma colegial. Las competencias de la Cámara de la Corte comprendían, entre otras, la supervisión y la dirección de las haciendas fiscales y de la Cámara, la cobertura de los gastos de la Corte y el control sobre el "presupuesto regio", o sea, del cálculo y distribución de los gastos militares. No obstante, su poder más prominente fue tal vez el control casi absoluto sobre los fondos financieros, eso es, el derecho a la asignación que ejerció hacia otras cámaras y cajas bajo su control: supervisaba las cámaras de países y provincias, presentaba proposiciones al soberano en cuanto a cuestiones financieras y de otra índole. Con la ayuda de los órganos de contabilidad a su lado, controló el funcionamiento y la gestión financiera de los empleados de las cámaras, así como a los oficiales de la minería, del comercio de sal y de la aduana. Las reformas de la administración en el siglo XVIII afectaron también a las competencias de la Cámara, ya que traspuso algunas funciones -como el de la tributación o de la gestión de los fondos-a la Cancillería. Su alcance territorial a partir de 1527 hasta su abolición en 1848 comprendió los territorios bajo continuo dominio Habsburgo (las Provincias Hereditarias, los países de la Sacra Corona de Hungría y de la Corona de Bohemia), y, hasta 1806, al Imperio Romano Germánico, además de los territorios temporalmente conquistados en Italia o en Polonia a lo largo de los siglos.

\section{La dirección militar y su lenta centralización: el Consejo de Guerra Áulico}

Paralelamente al aumento de la amenaza otomana, Fernando intentó centralizar la gestión militar, controlada firmemente por la nobleza. A partir de la década de 1520, aparecieron diversos consejeros de guerra en la Corte de Viena, que intervenían sobre todo en cuanto al frente húngaro, en campañas contra los otomanos y contra Juan I de Zápolya. Paralelamente a la centralización financiera, y motivada por los acontecimientos del frente húngaro, se inició también la centralización de la dirección militar; el proceso tuvo su punto culminante en el establecimiento del Consejo de Guerra Áulico (Hofkriegsrat, Consilium Aulum Bellicum). Sin embargo, se ha de tener en cuenta que la nobleza logró posiciones muy potentes en la gestión militar en varios períodos, sobre todo en el reino de Hungría.

Según su mandato, el Consejo de Guerra Áulico fue el responsable de todas las cuestiones militares, de transmitir las órdenes del soberano a los comandantes militares interesados; en tiempos de guerra, sus miembros tenían que planear la estrategia y distribuir las órdenes que sirvieran para que ésta se llevara a cabo. ${ }^{7}$ Este Consejo decidía, además, sobre las cuestiones personales más destacadas del ejército, como

\footnotetext{
${ }^{7}$ Géza Pálffy, „Die Akten und Protokolle des Wiener Hofkriegsrats im 16. und 17. Jahrhundert”, Quellenkunde..., 2004, 182-195.
} 
la designación de los comandantes de fortalezas, de los mandos de regimientos y del personal especializado (p. ej. ingenieros, encargados de los depósitos de armas, empleados de la artillería); y también tramitaba los documentos e instrucciones pertinentes a las designaciones, emitidos por la Cancillería del Consejo de Guerra. Dado que el Consejo de Guerra disponía sólo de posibilidades muy reducidas en cuanto a asignaciones financieras, intentaba mantener un conctacto continuo con la Cámara de la Corte para influir en las decisiones relacionadas con la financiación del ejército. ${ }^{8}$ También le correspondía el establecimiento de los límites del número del personal de los regimientos, el control del personal y su reposición necesaria, además de la organización del su abastecimiento, aunque en estrecha colaboración con la Intendencia Principal.

La Intendencia Principal (Generalkriegskommissariat), fundada a mediados del siglo XVII, funcionó bajo la Cámara de la Corte y el Consejo de Guerra Áulico, pero en ciertas ocasiones, en el mismo nivel también. Su deber fue asegurar el abastecimiento y el alojamiento (invernal) para el cuerpo del ejército regular -en proceso de formación-y para otras unidades, como las compañías libres y las tropas fronterizas, y supervisar su funcionamiento. Dado que los regimientos del ejército regular y las compañías libres constituyeron cierto tipo de unidad económica -disponían de ingresos, gastos y cajas regimentales- la exactitud de sus rendiciones de cuentas fue indispensable para calcular precisamente los gastos militares de la Monarquía. Además, la Intendencia Principal controlaba los efectivos de los regimientos, proveía la suplencia necesaria y, a base de los datos recibidos, controlaba también las provisiones y los otros servicios facilitados a los regimientos. También redactaba comunicados -a base de los informes recibidos de los regimientos y de otras unidades- y los presentaba en los foros decisorios de los órganos gubernamentales centrales. Cooperaba con la Oficina Principal de los Depósitos de Armas en la provisión de las fortalezas y de las demás unidades con municiones y armas de fuego. Se ve, por tanto, que la Intendencia Principal - provista de presidente, vicepresidente y varios consejeros-no pudo decidir por sí sola en muchos asuntos, por eso dependía notablemente de su capacidad de promover los propios intereses y, naturalmente, de la importancia del asunto en cuestión.

Su alcance territorial -hasta su abolición en 1848- comprendió del mismo modo las habituales regiones de la Monarquía de Austria. Es de notar todavía que entre 1578-1705, en Graz, funcionó otra intendencia independiente para gestionar la situación del frente abierto a lo largo de los ríos Drava, Sava, Una y Kolpa.

\footnotetext{
${ }^{8}$ András Oross, „Die für Ungarn zuständigen Kammern und die Kriegsfinanzierung der Habsburgermonarchie an der Wende vom 17. zum 18. Jahrhundert", Kriegführung und Staatsfinanzen. Die Habsburgermonarchie und das Heilige Römische Reich vom Dreißigjährigen Krieg bis zum Ende des habsburgischen Kaisertums 1740, Coord. Peter Rauscher. Münster, 2010 (Geschichte in der Epoche Karls V, Band 10) 297-310.
} 


\section{Los oficios reales y de los Estados húngaros ${ }^{9}$ \\ 6.1. Los escenarios húngaros de los preparativos y de la toma de decisiones: el Consejo Húngaro, el lugarteniente, el palatino y la Asamblea Legislativa}

En este capítulo se tratará de los ministros nombrados por el rey como por ejemplo los consejeros, el lugarteniente y por otra parte sobre la Asamblea Legislativa, ${ }^{10}$ el lugar más importante del ejercicio de los intereses y sobre el palatino elegido por los Estados Húngaros. ${ }^{11}$

Después de la pérdida de la batalla de Mohács y de la coronación de Fernando I la Corte Real Húngara se trasladó a Viena. El nuevo soberano, siguiendo el modelo del Consejo de su Corte, nombró a consejeros húngaros, aristócratas, dignatarios religiosos, considerados dignos de que en asuntos nacionales se les pidiera su opinión o escuchase sus consejos. Sus miembros eran dignatarios religiosos y profanos: arzobispos, obispos, cancilleres, el palatino, el lugarteniente, el "bán" de Eslavonia y Croacia, ${ }^{12}$ el juez de la corte (judex curiae), ${ }^{13} \mathrm{el}$ maestro del tesoro real (magister tavernicorum ${ }^{14}$ ), el juez de la tribunal de la presencia real (personalis praesentiae regiae in judiciis locumtenens), el lugarteniente del palatino (propalatinus, locumtenens palatinalis in judiciis), el el maestro de los conserjes (ianitorum regalium magister), el maestro de mesa real (dapiferorum regalium magister) el maestro de copas (pincernarum regalium magister), el dapifer, el maestro de la caballeria (agasonum regalium magister, mariscalchus), el mayordomo (magister curiae) y el presidente de la Cámara húngara. Había además consejeros sin rango nacional que recibían su posición gracias a la merced del rey.

Entre finales del siglo XV y principios del siguiente el Consejo húngaro que anteriormente había tenido que trasladarse de la Corte de Buda de los Jagellón a la corte de Viena, no formó un oficio que funcionara permanentemente en las siguientes décadas, puesto que los nombrados para estos rangos tampoco vivían permanentemente en la capital de la Monarquía de los Habsburgo, aunque varias decisiones de la Asamblea Legislativa inducían a que algunos de los consejeros permanecieran permanentemente en la Corte, no obstante, esta sugerencia del rey y de los Estados no llegó a materializarse. Hay que mencionar que teóricamente podían expresar su opinión en relación

\footnotetext{
${ }^{9}$ Estados húngaros (status et ordines): 1. prelados, 2. magnates, 3. nobles y 4. libres ciudades reales.

${ }^{10}$ Las palabras "asamblea", "asamblea legislativa" y "dieta" significan aquí lo mismo: la Asamblea Nacional (la Dieta) del Reino Húngaro.

${ }^{11}$ Géza Pálffy, „Valóságos és szimbolikus politikai kommunikáció. A magyar országgyülés helyszínei a 16-17. században" [Comunicación política simbólica y real. Los lugares de la Dieta húngara en los siglos 16-17], Rendiség és parlamentarizmus Magyarországon a kezdetektöl 1918-ig. [Nobleza y parlamentarismo en Hungría a partir de los principios hasta el año 1918], Coord. András Forgó et al. Bp.: Parlamenti Múzeum, 2013 (está en proceso de publicación).

${ }^{12}$ Bán (banus): el gobernador de Croacia.

${ }^{13}$ Judex curiae: uno de los jueces principales del Reino húngaro.

${ }^{14}$ En alemán: Schatzmeister.
} 
con cada asunto nacional, pero el Consejo Húngaro perdió mucho de su papel de preparación y de toma de decisiones, incluso de su papel de consejero, puesto que su opinión fue solicitada sólo a veces sobre los asuntos financieros, bélicos y exteriores a pesar de que estos asuntos se habían convertido en asuntos comunes por la guerra contra los turcos. La sede de sus sesiones tuvo lugar en la mayoría de los casos en Presburgo ${ }^{15}$ y en general discutían los problemas planteados por el rey en los tiempos de las dietas.

Ya hemos observado con respecto al Consejo de la Corte que el rango "consejero" para el siglo XVII llegó a ser un rango formal y lo mismo pasó con el Consejo Húngaro (consilium hungaricum). Al mismo tiempo el soberano convocaba la Asamblea Legislativa con cada vez menos frecuencia, por eso solicitaba la opinión del Consejo Húngaro en el siglo XVII en asuntos en los cuales anteriormente no lo había hecho. En aquellas décadas podían expresar su opinión sobre la Asamblea Legislativa, sobre la discusión de las propuestas reales, sobre las instrucciones para los embajadores, sobre las negociaciones de la paz, sobre la manutención de fortalezas fronterizas, además en relación con diferentes cuestiones jurídicas, la donación del título de "libre ciudad real" (civitas libera regia) y podían hablar sobre la solución de los problemas de las diferentes ciudades y provincias. Continuando este desarrollo, los consejeros húngaros conservando su título, llegaron a ser miembros de aquel consejo que funcionaba dentro de la Cancillería Húngara que para los finales del siglo XVII formaba parte de la administración. ${ }^{16}$

A partir del reinado de Segismundo de Luxemburgo (1387-1437) era costumbre que un lugarteniente (locumtenens) dirigiese los asuntos del país si el monarca permanecía en el extranjero. Fernando I abandonó el país justo después de su coronación y nombró por lugarteniente a María, la viuda del rey Luis II (1516-1526). A partir de 1535 un consejo especial, llamado Consejo del Lugarteniente, ayudó a la labor del lugarteniente, estando formado por aristócratas y dignitarios religiosos. Hasta la década de 1550, las tareas de los lugartenientes fueron creciendo, sobre todo en la época de tenencia del arzobispo Pál Várady (1542-1549), que se considera la época de esplendor de la tenencia por su papel desempeñado en la justicia y en la gobernación del país. La actividad de los lugartenientes para la segunda mitad del siglo XVI disminuyó y se limitó a la justicia -el tribunal del lugarteniente funcionaba como el tribunal supremo del país-. Mientras podemos considerar la segunda mitad del siglo XVI como la época de los lugartenientes del alto clero, después de 1608 los palatinos elegidos ocupaban el oficio de lugarteniente.

\footnotetext{
${ }^{15}$ Presburgo: Pozsony; Preßburg; hoy: Bratislava (SK).

${ }^{16}$ István Fazekas, „Die Verwaltungsgeschichte des Königreichs Ungarn und seiner Nebenländer (15261848)", Herrschaftsverdichtung, Staatsbildung, Bürokratisierung. Verfassungs-, Verwaltungs- und Behördengeschichte der Frühen Neuzeit, Hrsg. Michael Hochedlinger, Thomas Winkelbauer (Veröffentlichungen des Instituts für Österreichische Geschichtsforschung, 57.), Wien-München, Böhlau-Oldenbourg, 2010, 479-502.
} 
La mayor dignidad nacional después del rey en el Reino Húngaro fue el palatino (palatinus) a partir del Reinado de Esteban I El Santo (1000-1038). Antes de 1526 los palatinos ejercían el poder real en tres terrenos: como lugartenientes reales en la gobernación y en la justicia -eran los jueces supremos después del rey-y eran los capitanes generales del país en los asuntos bélicos. El Rey Matías Hunyadi (14581490) en el llamado artículo palatinal (1486) reguló las atribuciones del palatino y describió sus tareas. Lo más importante es que el palatino como oficial elegido por los Estados y nombrado por el rey desempeñaba un papel de mediación entre los Estados y el monarca, al mismo tiempo él convocaba las Asambleas en las que elegían al rey, incluso disponía del primer voto en esa ocasión. Después de la subida al trono de Fernando la situación cambió, puesto que el monarca, que permanecía en Viena, nombró a un lugarteniente de Hungría, por lo que el oficio del palatino varias veces quedó vacante entre los años 1533-1554, 1562-1608, 1667-1681 y 1732-1741. Hay que destacar con respecto a los palatinos de la edad moderna temprana que mientras iban perdiendo su función militar casi por completo, su papel desempeñado en la justicia, en la gobernación del país, en la administración pública y en la repartición de los impuestos iba aumentando. Tenían que cumplir las órdenes recibidas de las autoridades húngaras, de la Cancillería Húngara y eran participantes importantes en las tareas preparativas de las Asambleas. A partir del siglo XV tradicionalmente el palatino fue el juez supremo de los pueblos "jász" y "kun", además fue el prefecto de la provincia de Pest. En aquellos tiempos cuando la cargo del palatino no estaba ocupado, el monarca nombró a lugartenientes palatinales cuyas tareas abarcaban casi exclusivamente la justicia y desempeñaban papel importante en los procesos jurídicos.

Después de la sublevación dirigida por István Bocskai (1604-1606) se presentó la posibilidad de celebrar compromisos entre la Corte y los Estados, como lo muestra una decisión de la Asamblea sobre la elección de los palatinos, según la cual los Estados podían elegir al palatino de aquellas dos personas católicas y dos luteranos quienes fueron propuestas por el monarca; en el caso de la muerte de la persona elegida había que convocar la nueva Asamblea Electiva dentro de un año. En el caso de que el monarca no lo hiciera - dice el artículo de coronación del año 1608- lo podía hacer el juez de la corte o a falta de este el maestro del tesoro real por la continuidad de la ocupación de la posición del palatino.

Las tareas del palatino eran apoyadas por el creciente sistema de administración: subpalatinos, protonotarios y secretarios trabajaban en la cancillería del palatino. Los subpalatinos eran jurisprudentes nombrados y empleados por el palatino, quienes le ayudaban sobre todo en su trabajo como juez, mientras los protonotarios de la corte guardaban la estampilla palatinal y podían participar en inspección del lugar del hecho y en misiones, podían dar órdenes legales. Los palatinos no tenían sede fija, en general, su castillo servía como centro de su oficio. Como el cargo del palatino exigía muchas veces su presencia personal, tenía que viajar con frecuencia a Viena y a 
Presburgo tramitando asuntos políticos, mientras emitía los juicios en Nagyszombat ${ }^{17}$ o en Eperjes. ${ }^{18}$

En los siglos XVI-XVIII el lugar más importante del ejercicio de los intereses regios fue la dieta que fue convocada generalmente en Presburgo con algunas excepciones. El sistema de la dieta y la lista de los participantes fue fijada -según el desarrollo histórico- en la ley promulgada en 1608, siendo el primer artículo después de la coronación del mismo año.

Los miembros de la Cámara alta o de senado recibían una invitación personal del monarca: podían estar presentes los miembros del Consejo húngaro, los dignitarios religiosos -los arzobispos y obispos católicos-, los dignitarios nacionales y los de altos cargos de la Corte. Junto a ellos, a partir de la segunda mitad del siglo XVI, empezaban a aparecer cada vez en mayor número los aristócratas de la alta nobleza y los "indigenati", es decir las personas naturalizadas. La Cámara alta se reunía también en Presburgo, tradicionalmente en la casa del arzobispo de Esztergom. ${ }^{19}$

Con respecto a la Cámara baja o Cámara de los Diputados, el cambio más importante, comparada la situación con la de la Edad Media, fue la desaparición de la participación personal de la nobleza, en vez de ellos las provincias eran representadas en las dietas por dos o tres personas enviadas por aquéllas. La nobleza, por su parte, que se iba empobreciendo, no podía sufragarse la estancia de varios meses en Presburgo, porque a veces incluso para las provincias también era difícil pagar los altos gastos del viaje. La dieta unida de Eslavonia y de Croacia también se hacía representar de modo semejante a las provincias, mandando a dos o tres personas. Las ciudades reales libres, los prepósitos y los cabildos también mandaban diputados, pero el superior de los monjes paulinos (Ordo Sancti Pauli Primi Eremitae) podía estar presente personalmente. Se añadían a ellos las viudas de los magnates, los agentes de los magnates que no podían participar personalmente, además de la planta completa del Tribunal Real (Tabula Regia), como organización suprema de la justicia. El presidente de la Cámara alta era el palatino, el de la Cámara baja era el juez del tribunal de la presencia real (Personalis presentiae regiae).

Durante los preparativos de la Asamblea el rey comunicaba en una carta de invitación los asuntos para discutir con los Estados. Las provincias, conocedoras de estos asuntos, daban instrucciones a los diputados, quienes tenían que seguirlas durante las discusiones de los diferentes asuntos en la Cámara baja. Además de discutir las propuestas reales, los Estados tenían la posibilidad de presentar sus problemas y sus solicitudes y el rey les daba respuesta en escrito. Las dos Cámaras naturalmente tenían sus sesiones aparte y tomaban las decisiones separadamente, no obstante, en la Alta Edad Moderna la Cámara alta disponía de mayor peso, mientras la importancia de la

\footnotetext{
${ }^{17}$ Nagyszombat (Tyrnau; Tyrnavia/Tyrnaviae; hoy: Trnava (SK).

${ }^{18}$ Eperjes, hoy: Prešov (SK).

${ }^{19}$ Esztergom, HU (en latín: Strigonium; en alemán: Gran).
} 
Cámara baja empezó a aumentar a finales del siglo XVIII, y alcanzó su cumbre durante las dietas de la era de las reformas. Los Estados mantenían la relación con el monarca mediante la Cancillería Húngara y si llegaban a un acuerdo con respecto a un asunto importante, entonces se empezaba la redacción del texto de la ley, que era ratificado por el rey después de haber sido aceptado por la Asamblea Legislativa. La promulgación de la ley significaba su entrada en vigor y la norma era mandada a las diferentes autoridades jurídicas.

Las dietas de la época moderna temprana podían consultar sobre cualquier asunto nacional, pero por el peligro turco eran muy frecuentes las decisiones sobre el funcionamiento normal del sistema de la defensa de las fronteras, como por ejemplo el trabajo gratuito y obligatorio en las fortalezas, es decir, las prestaciones financieras. Se puede considerar el objeto más importante el derecho de la dieta de presentar propuestas sobre los impuestos: las convocadas en el siglo XVI no podían concluirse sin tomar alguna decisión sobre los impuestos. A partir de los mediados del siglo XVII el sistema fue modificado, puesto que el monarca convocaba la Asamblea cada vez menos y gobernaba más bien a través de edictos reales. No obstante, el impuesto ofrecido en la dieta podía ser recaudado hasta la próxima dieta, es decir, la oferta de un impuesto era válida durante varios años. En esta época calculaban el impuesto militar según las necesidades del ejército e intentaban que fuera aceptado en las reuniones al efecto por los jefes políticos del país, por las provincias y por los diputados de las ciudades, después lo repartían entre las autoridades judiciales.

\subsection{Gestión política y jurisdicción: la Cancillería Real Húngara de la Corte}

Hemos observado en la presentación de la Cancillería de la Corte que podía ejercer su actividad junto al monarca del momento. Tradicionalmente, el arzobispo de Esztergom encabezaba la Cancillería Real Húngara de la Corte (Cancellaría Aulica Hungarica) con el título del canciller superior, no obstante, el oficio fue dirigido en la realidad por el canciller, uno de los obispos.

Los secretarios de la Cancillería húngara aparecieron también al lado del Fernando, coronado después de la pérdida de la batalla de Mohács, quienes apuntaban y emitían las decisiones sobre los asuntos húngaros. Uno de los nueve departamentos de la Cancillería de la Corte, el llamado expeditio húngara, bajo la dirección del secretario húngaro, tramitaba los asuntos relacionados con el Reino Húngaro. Las decisiones del monarca eran redactadas por los secretarios reales siguiendo las órdenes del canciller de la corte, después las minutas se ponían en limpio con la ayuda de escribanos. Los documentos listos -si estaban en Viena- eran firmados por los cancilleres, pero también es frecuente que podemos encontrar solamente la firma del rey y del secretario. ${ }^{20}$

\footnotetext{
${ }^{20}$ Győző Ember, „Magyarország közigazgatása, 1711-1765” [La administración pública de Hungría, 1711-1765] Levéltári Közlemények, 54, 1983, pp. 1-2 y 8-17.
} 
Las competencias de la Cancillería Húngara en los siglos XVI-XVII abarcaban ante todo los asuntos de jurisdicción y de mercedes y también las negociaciones diplomáticas con Transilvania, Polonia, Moldavia, Havasalföld (Valachia), los informes de los embajadores turcos y las propuestas de las autoridades austríacas y bohemias al rey húngaro. Las propuestas escritas por el Consejo Húngaro también pasaban a través de la cancillería al monarca. El secretario hacía de cada asunto un resumen, adjuntaba su opinión y ciertos días de la semana el canciller lo trasmitía al rey o él mismo se lo enseñaba personalmente en las sesiones del Consejo Secreto.

La intención más importante de los Estados húngaros -según el cual el rey debería tramitar los asuntos húngaros a través de la cancillería- en muchos casos no se cumplía, porque en una monarquía tan compleja como la de los Habsburgo apenas había asuntos exclusivamente húngaros. Finalmente, los Estados en la Dieta del año 1569 en su artículo XXXVIII reconocieron que existían asuntos mixtos y asuntos húngaros y aceptaron que el rey tenía la obligación de tramitar solamente estos últimos por medio de los oficios húngaros.

Paralelamente a la expulsión de los turcos se iniciaba la preparación del sistema administrativo nuevo del Reino Húngaro, que ejercía influencia sobre la gobernación del país también. En 1690 empezó una nueva época en la vida de la cancillería húngara. Recibió instrucciones del monarca que decían que cuatro consejeros y dos secretarios tenían que permanecer continuamente junto al rey, además que los asuntos habían de ser tratados en el Consejo de la cancillería. La Cancillería Húngara se convirtió en una autoridad gubernamental de la corte en ese momento y funcionaba sobre la base territorial con un procedimiento determinado. Las instrucciones determinaban las tareas principales de la cancillería: guardar la dignidad monárquica, el respecto de los derechos reales y hacer valer las leyes, las órdenes reales y las sentencias de los jueces en el país. Las competencias de la cancillería después de 1690 se ampliaron significativamente: además de los asuntos de mercedes, de clemencia y de jurisdicción, le pertenecía el control de la dirección y de la economía de las provincias, de las libres ciudades reales y de los terrenos especiales, además la vigilancia de los asuntos del erario.

\subsection{Los asuntos financieros del Reino Húngaro: el sistema de la Cámara}

Durante los casi dos siglos transcurridos entre la batalla de Mohács y el tratado de paz de Szatmár $(1711)^{21}$ en el territorio del Reino Húngaro existieron varias organizaciones de dirección financiera, es decir, cámaras que funcionaban sobre base territorial. No obstante, en el momento de la subida al trono de Fernando I todavía

\footnotetext{
${ }^{21}$ La paz de Szatmár (1711) fue el acto final del último levantamiento de los húngaros contra los Habsburgo en la época moderna (1703-1711); el líder de la guerra de independencia era el príncipe Francisco II Rákóczi.
} 
funcionaba el sistema del tesoro real. Debido a las reformas fiscales introducidas durante el reinado de Matías Hunyadi (1458-1490), la tarea más importante del tesorero -cuyo poder iba aumentando- fue el manejo de los ingresos regios, es decir, vigilaba las cámaras de la sal, los oficiales de las minas, las oficinas aduaneras del comercio exterior y los impuestos llamados treintavos. El tesorero superior tenía un sistema de administración original y tenía que presentar las liquidaciones regularmente al consejo real. El tesorero era en la mayoría de los casos de origen aristócrata y sus familiares eran empleados en la oficina, así, los Estados -sobre todo durante la época de los Jagellones- ocupaban altos cargos en la dirección fiscal. No obstante, con la introducción de las reformas de Matías Hunyadi se separaron los ingresos de origen de los latifundios reales: así el juez de la corte (comes curiae) de Buda manejaba estos importes sin la intervención de los Estados.

Sin embargo, Fernando no quería mantener ese sistema originado en la Edad Media, así, en 1528 fundó la Cámara Húngara (Camera Hungarica) en Buda, y la reorganizó a lo largo de los siguientes años según el modelo de la Cámara de la Corte (presentada anteriormente). Su tarea abarcaba el manejo de los ingresos adquiridos a partir de los derechos reales y, al mismo tiempo, tenía un papel destacado en la administración del impuesto militar. Hay que mencionar entre las tareas del manejo de los ingresos reales los quehaceres relacionados con los asuntos de los latifundios del tesoro real, de la dirección y de la economía de los dichos latifundios, los asuntos del impuesto llamado treintavo, las regalías de las minas y de la sal, los asuntos de la acuñación, las cuestiones relacionadas con el control de las libres ciudades reales y los relativos al manejo de los asuntos de la cámara en relación con los latifundios eclesiásticos. Los monarcas nombraban a los directores de la organización con el título de administrador, más tarde con el de presidente y los encomendaban a consejeros, contables y cajeros también. En el siglo XVI normalmente obispos y arzobispos ocupaban esta alta posición, quienes al mismo tiempo eran lugartenientes también, en cambio en el siglo XVII más bien fueron aristócratas de la élite política las personas quienes encabezaban la Cámara Húngara.

Con el paso del tiempo el monarca restringió sus competencias, puesto que algunos ingresos fueron controlados, no por la Cámara Húngara (que estaban en Presburgo), sino por otras organizaciones fiscales fundadas con el mismo objetivo. Significaban ingresos elevados los treintavos del oeste de Hungría (Presburgo, Magyaróvár), los señoríos del tesoro (Komárom, ${ }^{22}$ Magyaróvár, ${ }^{23}$ Zólyom ${ }^{24}$ ), además la minería y la acuñación de Hungría Baja [Hungría Inferior] (la Cámara de Körmöcbánya ${ }^{25}$ ). Estos oficios fueron sometidos a la Cámara de Austria Inferior (Niederös-

\footnotetext{
${ }^{22}$ Hoy: Komárno, SK.

${ }^{23}$ Magyaróvár, hoy: Mosonmagyaróvár, HU.

${ }^{24}$ Zólyom; Altsohl; Zvolen (SK).

${ }^{25}$ Kremnitz; Kremnica (SK).
} 
terreichische Kammer), lo que fue un hecho importante, porque una gran parte de los ingresos reales se originaba de los terrenos arriba mencionados.

$\mathrm{Su}$ competencia territorial iba disminuyendo paralelamente a la conquista turca, no obstante, con respecto a sus órdenes seguía siendo competente en todo el Reino Húngaro. Esto significaba que junto a Hungría, teóricamente podía disponer de los ingresos de Eslavonia, Croacia y de Transilvania. La primera restricción de sus competencias fue en 1567, porque en aquel momento fundaron la Cámara de Szepes ( $\mathrm{Ca}$ mera Scepusiensis) con sede en Kassa ${ }^{26}$ para controlar la dirección fiscal de Hungría superior. La nueva organización fiscal tenía competencias territoriales en las provincias de Szepes, Sáros, Abaúj, Torna, Gömör, Pest, Solt, Borsod, Heves, Zemplén, Ung, Bereg, Ugocsa, Máramaros, Szatmár, Szabolcs, Szolnok (Interior, Central y Exterior), Kraszna, Bihar, Békés, Zaránd, Csongrád, Csanád, Arad, Torontál y Temes.

La reorganización más importante en el sistema de la cámara ocurría paralelamente a la expulsión de los turcos, entre finales del siglo XVII y principios del siglo siguiente. Junto a las cámaras de Presburgo, Kassa y las de las ciudades mineras, aparecieron las organizaciones fiscales dependientes de la Corte de Viena que tenían unas competencias fiscales más limitadas territorialmente y su funcionamiento era menos duradero. Después de 1686 fundaron la Administración de la Cámara de Buda, al que pertenecían todos los territorios adquiridos nuevamente, así estaba en una continua discusión de competencias con las otras cámaras. En la parte oriental del territorio entre los ríos Dráva (Drava) y Száva (Sava) se organizó la Inspección de las Cámaras de Eslavonia, su sede estaba en Eszék, ${ }^{27}$ y funcionó durante el siglo XVIII. En 1670 la corona adquirió la administración de los señoríos confiscados de las familias Zrínyi y Frangepán, que se encontraban en Muraköz ${ }^{28}$ y en las costas del mar Adriático. Para dirigirlos organizaron una administración aparte bajo la dirección de la Cámara Húngara. Las tareas más importantes del sistema nuevo fueron -con respecto a los años bélicos- ante todo la manutención de los ejércitos y el aseguramientode los derechos del tesoro real, mientras las tareas clásicas fueron relegadas a segundo plano. Después de la expulsión de los turcos dichas organizaciones fueron eliminadas pasando sus competencias a la Cámara Húngara. Las competencias territoriales de la Cámara Húngara fueron reconstituidas a base del artículo XIV del año 1741 en el que declararon que sus tareas abarcaran los asuntos de la sal y de las minas también.

Finalmente, es necesario destacar que Transilvania -después de la edición del $D i$ ploma Leopoldinum del año 1690- quedó anexionada definitivamente a la Monarquía Húngara: Leopoldo I y sus consejeros consideraban que Transilvania había pasado a los Habsburgo por derecho de guerra. Las dificultades de la situación política, la des-

\footnotetext{
${ }^{26}$ Kassa, Kaschau; Košice (SK).

${ }^{27}$ Eszék; Osijek (HR).

${ }^{28}$ Murinsel - alemán; Međimurje - croata; Medžimurje - esloveno.
} 
confianza y la inseguridad (el temor de que el territorio fuera conquistado de nuevo por los turcos) condujo al hecho de que en el terreno del manejo de los ingresos en los años 1690 la mayoría de los deseos fiscales de la aristocracia de Transilvania fueron cumplidos, asegurando así su fidelidad a Viena. Esto significaba que podían llegar a un compromiso político y económico con la élite de Transilvania que serviera a los intereses de ambos interesados. Con respecto a las regalías y a los latifundios del tesoro real, se introdujo un sistema de alquiler (appaldo), según el cual ciertos aristócratas y compañías recibían el usufructo del dicho ingreso adelantando cierto importe -según el contrato durante varios años-. Aunque los asuntos financieros de aquel territorio fueron dirigidos por el tesorero elegido por los Estados que ejercía su actividad bajo la dirección de la Cámara de la Corte, en realidad, los latifundios con los mayores ingresos se alquilaban.

\subsection{El escenario de la administración pública de nivel intermedio y el de la autonomía de la nobleza: la provincia}

La administración pública de nivel intermedio del Reino Húngaro en los siglos XVI-XVII por la conquista otomana fue la tarea de las provincias (comitatus, Gespannschaft) cuyo número no era fijo. Mientras a principios del siglo XVI las autoridades legales de las áreas ocupadas por los turcos mantenían su actividad solamente durante corto tiempo, a partir de los años 1550-60 las provincias conquistadas -fuera de su territorio- cumplían con sus tareas, incluso podían controlar su ex-territorio con ayuda militar. Podemos encontrar varios casos característicos de aquella época: la provincia de Pest por ejemplo mantenía su organización en Nógrád, mientras las provincias de Heves, Szolnok Exterior o las de Zala y Somogy fueron unidas a base de la ley promulgada por la Asamblea Legislativa (los artículos LII del año 1569 y el VII del año 1596). Se adjuntó a las treinta provincias que funcionaban durante la dominación otomana unas 10-15 autoridades jurídicas más después de la expulsión de los otomanos. El foro político más importante de la provincia era la asamblea general de la provincia, convocada por el prefecto nombrado por el monarca; además la provincia de vez en cuando organizaba juzgados que funcionaban como tribunales de primera instancia para la nobleza provincial. ${ }^{29}$ En las asambleas leían y discutían las órdenes reales, las del palatino y de la cancillería, tomaban decisiones con respecto a los asuntos más importantes y elegían a los oficiales provinciales y a los diputados. En los siglos XVIXVII las tareas de la provincia fueron -por la presencia otomana- la defensa contra los turcos, los impuestos, la manutención del ejército y los quehaceres administrativos

\footnotetext{
${ }^{29}$ Péter Dominkovits, „Das ungarische Komitat im 17. Jahrhundert. Verfechter der Ständerechte oder Ausfrührungsorgan zentraler Anordnungen?", Die Habsburgermonarchie 1620 bis 1740. Leistungen und Grenzen des Absolutismusparadigmas, Hrsg. Petr Mata-Thomas Winkelbauer. Stuttgart, Franz Steiner, 2006 (Forschungen zur Geschichte und Kultur des östlichen Mitteleuropa, 24), 401-441.
} 
relacionados con los dichos asuntos. Todos los nobles que disponían de señorío -sin tener en cuenta su fortuna- tenían el derecho y al mismo tiempo -bajo el cargo de una posible multa- la obligación de estar presentes personalmente o representados por un encargado en la asamblea hasta el siglo XVII. Llegado, tenía que permanecer en la asamblea hasta el final y participar en la toma de las decisiones. Las asambleas generales se convocaban sin regularidad, según las necesidades, y en la toma de las decisiones no contaban los votos si no lo consideraban necesario. Las decisiones eran fijadas en un expediente que guardaban después en el archivo de la provincia.

Los prefectos nombrados por el monarca encabezaban las provincias. En varias provincias la posición del prefecto se convirtió en una situación hereditaria, como por ejemplo en el caso de la provincia de Győr el obispado o la prefectura hereditaria en la provincia de Szatmár donde la familia Károlyi ocupaba la posición del prefecto, pero hemos visto también que en la provincia de Pest el prefecto era el palatino. El prefecto representaba los intereses del monarca en la gobernación de la provincia. Sus competencias eran: nombrar a los oficiales para aquellos puestos que no fueron ocupados por elección provincial (vicenotarios); encargos temporales -en el caso de los vacantes hasta la convocatoria de la asamblea siguiente- presidir en las asambleas y en los diferentes comités, controlar la administración pública en la provincia.

El ministro principal de la provincia fue el viceprefecto, elegido por la asamblea como los otros oficiales de la provincia, así como los alcaldes, jurados, recaudadores, notarios. El viceprefecto dirigía la administración de la provincia y a los oficiales subalternos, presidía las asambleas en el caso de la ausencia del prefecto, ejecutaba las decisiones centrales y las de la asamblea provincial. Los jueces de los nobles (iudex nobilium) eran ministros a la cabeza de los diferentes distritos de la provincia, había 4-8 en cada provincia; su tarea consistía en mantener las relaciones entre la provincia y los pueblos con respecto a los diferentes asuntos, como por ejemplo la ejecución de las órdenes de la cancillería, la obligación de pagar los impuestos o del alojamiento o el mantenimiento de la seguridad ciudadana. El notario en la administración provincial redactaba las decisiones y los reglamentes, ponía en limpio los expedientes de las asambleas y las notas, además de las publicaciones de la provincia. Con la diversificación de la administración de las provincias en la segunda mitad del siglo XVII se extendió el cargo de recaudador quien controlaba y realizaba la recaudación de los diferentes impuestos militares y provinciales.

Podemos conocer las provincias de la Alta Edad Moderna por las ejecuciones de las órdenes palatinales y de las decisiones reales que llegaban allí a través de la Cancillería Real Húngara de la Corte. Tenían un papel importante en la jurisdicción y en la administración de los impuestos, si bien con respecto a los asuntos religiosos tuvieron conflictos graves con el poder central. La oposición de los Estados -que permanece hoy viva en-se formó solamente a finales del siglo XVIII y alcanzó su cumbre en los conflictos de las dietas de la época de las reformas. 


\subsection{Gobierno y organización interna de las ciudades del reino de Hungría: el ejemplo de las ciudades reales libres}

Las ciudades del reino de Hungría en la temprana Edad Moderna se dividen en varios tipos según su situación legal: ${ }^{30}$ ciudades reales libres (civitas libera regia, civitas), que pueden dividirse a su vez según la institución a la cual debían dirigirse con recursos: las ciudades tavernicales pertenecientes al tesorero (Buda, Presburgo, Sopron, ${ }^{31}$ Nagyszombat, ${ }^{32}$ Kassa ${ }^{33}$, Eperjes,${ }^{34}$ Bártfa,,${ }^{35}$ y a partir de 1481 Pest) y las ciudades pertenecientes al jefe del Tribunal Supremo (Óbuda, ${ }^{36}$ Estrigonia, Székesfehérvár ${ }^{37}$ Lőcse, ${ }^{38}$ Szakolca ${ }^{39}$, Kisszeben ${ }^{40}$ y Szeged ${ }^{41}$ ). En cuanto a la relación legal con el soberano, algunas ciudades mineras del norte de Hungría tenían una situación especial (las más importantes: Besztercebánya ${ }^{42}$ Körmöcbánya ${ }^{43}$ y Selmecbánya ${ }^{44}$ ).

Se calificaban como ciudades reales libres aquellas que disponían del círculo más amplio de los privilegios y las libertades que las separaban de su entorno, y que habían recibido de forma legal del soberano coronado legítimo. En la jerarquía legal, la ciudad real libre se consideraba persona jurídica nobiliaria, ligada a la libertad nobiliaria colectiva, y cuyos habitantes, ciudadanos de pleno derecho (cives), tenían los mismos privilegios otorgados a la ciudad entera.

Las ciudades reales libres, iguales en su condición jurídica, nunca fueron completamente iguales en su estructura arquitectónica, papel económico, importancia, número de habitantes, estructura social e, incluso, en sus privilegios y deberes. La base constitutiva de los derechos de una ciudad libre real fue el diploma de privilegio, emitido exclusivamente por el soberano. Privilegiándola, el monarca sustrajo a la ciudad de la autoridad del prefecto, de la provincia y de cualquier juez: declaró persona nobiliaria la universidad libre y privilegiada de los habitantes (universitas), que podía así valerse de la libertad nobilitaria y devino uno de los terratenientes de

\footnotetext{
${ }^{30}$ István H. Németh, Städtepolitik und Wirtschaftspolitik in Ungarn in der Frühen Neuzeit. Geteilt - Vereingit. Beiträge zur Geschichte de Königreichs Ungarn in der Frühneuzeit (16.-18. Jahrhundert), Hrsg.: Krisztián Csaplár-Degovics - István Fazekas. Berlin, 2011 (Edition ungarische Geschichte, 1) 329-355.

${ }^{31}$ Sopron, HU.

${ }^{32}$ Trnava, SK.

${ }^{33}$ Košice, SK.

${ }^{34}$ Prešov, SK.

${ }^{35}$ Bardejov, SK.

${ }^{36}$ La parte más antigua de Buda (hoy es un distrito de Budapest).

${ }^{37}$ Székesfehérvár (en latín: Alba Regia, HU).

${ }^{38}$ Levoča, SK.

${ }^{39}$ Skalica, SK.

${ }^{40}$ Sabinov, SK.

${ }^{41}$ Szeged, HU.

${ }^{42}$ Banská Bystrica (en alemán: Neusohl), SK.

${ }^{43}$ Kremnica (en alemán: Kremnitz), SK.

${ }^{44}$ Banská Štiavnica, (en alemán: Schemnitz), SK.
} 
la ciudad. Los privilegios autorizaron la comunidad al autogobierno y a la inmunidad. Los ciudadanos de pleno derecho fueron electores y elegibles a los cargos del municipio local; por lo tanto, fueron ellos mismos quienes elegían a sus líderes, al juez (iudex) -a veces al alcalde también-, al concejo (senatus, magistratus) y a los ministros. ${ }^{45}$

Entre las ciudades reales libres existían diferencias enormes en el número de habitantes, y en varios aspectos, por ejemplo, económicos. Los índices demográficos del reino de Hungría no se han de comparar con los de las regiones más urbanizadas de Europa (Provincias Unidas de los Países Bajos, Italia del Norte), dado que en éstas el número de los habitantes se multiplicó en los siglos XVI-XVII. A comienzos de la Edad Moderna, en el reino unido de Hungría, había 30 ciudades reales y unas 150 villas (oppidum, Markt) que pueden considerarse importantes centros económicos, administrativos y culturales de la época; en ellas vivía unos 7-8\% de la población del país. En la mayoría de los casos, las ciudades reales, comparadas a la red de ciudades de Europa occidental, fueron ciudades de tamaño mediano o pequeño. Antes de la ocupación otomana, fue sólo Buda (12.000-15.000 habitantes) la única ciudad considerable, pero desde el segundo cuarto del siglo XVI su papel económico y el número de sus habitantes empezaron a decaer fuertemente. Pest y Szeged se acercaban a los diez mil habitantes, Presburgo tenía unos 5.200-5.400 a mediados del siglo XVI; Kassa unos 4.000-5.000, y 6.000-7.000 en el siglo XVII; Trnava unos 4.000-5.000 a finales del siglo XVI; Debrecen, en la segunda mitad del siglo XVII, se convirtió en la ciudad más numerosa con unos 10.000-12.000 habitantes. Los centros nacionales y regionales más importantes de la Baja Edad Media (Buda, Pest, Szeged, Presburgo, Trnava, Kassa, Nagyvárad, ${ }^{46}$ Pécs, Sopron, Besztercebánya ${ }^{47}$ y Kremnica) pasaron a las manos de los otomanos y Oradea adquirió funciones bien diferentes, de fortaleza fronteriza occidental para el Principado de Transilvania. Presburgo, antes centro regional, se promovió a centro administrativo dando lugar a la sede de la Cámara de Hungría y a otros órganos gubernamentales; Viena, centro de la Monarquía de los Austrias, se convirtió en capital del reino de Hungría. Desde el punto de vista administrativo, la situación de algunas ciudades reales fue complicada: Presburgo, Kosiče y hasta cierto punto Trnava (convertida en centro eclesiástico y cultural) obtuvieron funciones mucho más amplias; su nueva importancia se originaba por la instalación de órganos administrativos de gran relieve.

A la cabeza de las ciudades reales libres estaba el juez, y el órgano decisorio principal fue el concejo reducido (senatus, magistratus) de 12 personas. En la mayoría de los casos, los miembros de este gremio y sus familias constituían la élite política.

\footnotetext{
${ }^{45}$ István H. Németh, „Venerable Senators or Municipal Bureaucrats? The Beginnings of the Transformation of the Estate of Burghers at the Turn of the Seventeenth and Eighteenth Centuries", The Hungarian Historical Review, 1, 2012, 1-2, 49-78.

${ }^{46}$ Oradea, RO.

${ }^{47}$ Banská Bystrica, SK.
} 
El primer oficial fue el juez (judex, Richter, scultetus), que supervisaba el trabajo de los demás subalternos y representaba la comunidad de los ciudadanos hacia afuera. Entre sus competencias se unían las administrativas con las jurisdiccionales. Este sistema directivo funcionó en Buda, Kassa, Nagyszombat (Trnava), Szeged, Pécs y Temesvár, ${ }^{48}$ entre otras. Los estatutos de muchas ciudades (como el de Besztercebánya) exigía ciertas condiciones morales y financieras por parte del futuro juez, que debía disponer también de conocimientos jurídicos.

Un sistema diferente podía formarse mediante la aparición del oficio del alcalde (magister civium, Bürgermeister) al lado del juez. En Presburgo y Sopron, a partir de finales de la Edad Media, el alcalde iba asumiendo las funciones administrativas. Al inicio se ocupaba sólo de tareas de menor importancia, pero más tarde ya le correspondía gestionar las finanzas, preparar y controlar la rendición de cuentas de la ciudad y ejecutar las disposiciones del concejo. En teoría, tenía que dar cuenta del estado económico de la ciudad ante la comunidad de los ciudadanos, pero, por ejemplo, en Presburgo se limitaba a la presencia de algunos miembros del concejo amplio (de 60 personas) durante el informe del alcalde ante el concejo reducido, pero en ningún caso estaba presente el concejo amplio al completo. La separación de las competencias del juez y el alcalde se manifestaba también a nivel de las insignias: al juez le correspondía el sable judicial y al alcalde, su vara. Otra personaje importante en la administración urbana fue el notario cívico (Stadtschreiber, notarius) que preparaba las actas de las sesiones del concejo y dirigía el archivo; su sueldo fue sustancioso debido a que fue el jefe de la administración urbana; el nombre del notario aparece con frecuencia al final de documentos privados, por ejemplo, en testamentos. Otra figura clave de la economía urbana fue el responsable de la cámara cívica (Kammerer) que en muchos lugares preparaba las rendiciones de cuentas a partir de la segunda mitad del siglo XV. Las ciudades mayores empleaban también un procurador cívico (Stadtprocurator), una matrona y un médico también. En la mayoría de los lugares creció asimismo el papel del capitán cívico (Stadthauptmann): debido a las cuestiones del estacionamiento militar y de la defensa, intervenía en el comercio inmobiliario también. Además de esto, fue responsable de vigilar el orden y en Presburgo podía incluso administrar justicia en causas menores.

\subsection{Croacia y Eslavonia}

En los siglos XVI y XVII las circunstancias de la administración pública y de gobernación del Reino Croata -que se encontraba en unión personal con el Reino Húngaro desde 1102 - fueron determinadas por la conquista otomana ${ }^{49}$ Mientras durante

\footnotetext{
${ }^{48}$ Timişoara, RO.

${ }^{49}$ Géza Pálffy, „Rendkívüli források a horvát nemzeti szimbólumok történetéhez: Horvátország zászlajának legkorábbi ábrázolásai a 16-17. századból" [Fuentes archivisticas extraordinarias para la historia
} 
los siglos de la Edad Media la parte oriental del territorio entre los ríos Dráva y Száva formó parte de Hungría (en aquella época se llamaba Croacia el territorio que se encontraba entre el mar Adriático y la montaña de Kapela y Eslavonia era aquel territorio que se encontraba entre los ríos de Dráva y Száva, además pertenecían a Eslavonia los territorios de las provincias de Zágráb, ${ }^{50}$ Körös $^{51}$ y Varasd ${ }^{52}$ ), estos conceptos históricos-geográficos se cambiaron a finales del siglo XVII. ${ }^{53}$ En esa época Croacia tenía nuevas fronteras: se encontraba en los territorios que estaban al oeste del río Una y los territorios entre los ríos Dráva y Száva que antes de Mohács formaba parte de Eslavonia. El concepto de Eslavonia también cambió, pues a finales del siglo XVII así se denominaba a la parte oriental del territorio que se encontraba entre los ríos Dráva-Danubio-Száva, que antes de Mohács pertenecía a Hungría directamente. Los Estados croata y eslavón a principios del siglo XVI se reunían regularmente y de forma separada, pero después se unieron; la prueba de este hecho es que después de 1588 organizaban las asambleas conjuntamente. Las decisiones aprobadas por los Estados croata y eslavón no podían ser contrarios a las leyes húngaras y tenían que ser aprobadas por el rey.

La dirección de los territorios croata-eslavones era dirigida por el "bán", quien desempeñaba un papel muy importante no solamente en los asuntos interiores y en la administración pública, sino también en la guerra también, pues disponía de una función militar muy importante como jefe militar de la zona fronteriza, mandando unos 500 soldados.

\subsection{Los «caminos separados» de Transilvania}

La evolución del sistema administrativo de Transilvania en los siglos XVI-XVII muestra similitudes con el de la parte de Hungría gobernada por la Casa de Austria, pero en otros rasgos conserva el sistema gubernamental consolidado en la Edad Media.

Al frente del estado de Transilvania estaba el príncipe, de iure elegido por la Asamblea de Transilvania, pero su elección no se consideraba efectivamente convalidada hasta la emisión de un diploma solemne (athanamé) por parte del sultán. Las competencias del príncipe se entienden a partir de su relación con los otomanos, puesto

de los símbolos nacionales de Croacia: las representaciones más antiguas de la bandera de Croacia de los siglos 16 y 17], Ünnepi tanulmányok Bak Borbála 70. születésnapjára. Ed. Kádár Zsófia-Lakatos Bálint-Zarnóczki Áron. Bp., 2013 (está en proceso de publicación).

${ }^{50}$ Zagreb, HR.

${ }^{51}$ Križevci, HR.

${ }^{52}$ Varaždin, HR.

${ }^{53}$ Géza Pálffy, „Horvátország és Szlavónia a 16-17. századi Magyar Királyságban” [Croacia y Eslavonia en el Reino húngaro en los siglos XVI-XVII], Fons (Forráskutatás és Történeti Segédtudományok), 9, 2002, 1-3, 107-121. 
que fue él quien comandaba los asuntos militares y exteriores, pero exclusivamente con la aprobación del sultán. Si el príncipe transilvano emprendía una política exterior independiente, tal vez desafiando hasta al sultán mismo, podía causar graves conflictos, con frecuencia incluso armados. Por otro lado, el poder principesco transilvano puede considerarse casi absoluto, en el sentido de que podía contar con una oposición casi nula por parte de la nobleza, y disponía de una amplia autonomía en cuestiones financieras e interiores. ${ }^{54}$

En la preparación de decisiones y la toma de disposiciones lo ayudaba el Consejo Principesco que se componía de representantes de las tres naciones (húngara, székely y sajona) en proporciones iguales, a cuyo lado trabajaban miembros nombrados por el príncipe. El personaje más importante del consejo fue el canciller que funcionaba a su vez como presidente de la administración transilvana. La Asamblea unicameral de Transilvania tenía dos sesiones anuales, en las cuales participaban no sólo los delegados de la Transilvania Interior, sino también los de las provincias de Transilvania Exterior occidental. La Asamblea disponía del derecho a recomendar impuestos y a expresar su parecer en asuntos exteriores. El tesorero también tenía un encargo de importancia: gestionaba las finanzas del estado. En los tiempos del Principado independiente de Transilvania no existieron autoridades de funcionamiento continuo y colegial como la Cámara de Hungría o el Consejo de Lugartenencia; órganos de este tipo se establecieron sólo después de la inserción de este estado en la Monarquía de los Austrias.

\subsection{Una mirada al período postotomano: el gobierno de Hungría em los siglos XVIII-XIX: el Consejo de Lugartenencia}

El Consejo de Lugartenencia (Consilium Regum Locumtenentiale Hungaricum), establecido con el artículo XCVIII del año 1723, fue un órgano gubernamental real. Dependía de la voluntad del soberano, en un nivel secundario entre las oficinas áulicas centrales y la baja administración local en todo el país, con la excepción de Transilvania, la Frontera Militar y el Banato de Tamis (hasta 1778), incluso -con breves interrupciones- en Eslavonia y en Croacia. ${ }^{55} \mathrm{Su}$ función fue de segundo grado, sobre todo ejecutivo, debajo de los órganos áulicos centrales de grado superior, que influían directamente en las decisiones del soberano, de modo que el Consejo fue el ejecutor de la voluntad del soberano en los países donde él no residía. Su competencia abarcaba la administración interior en su sentido más amplio, excluidos la gestión de las posesiones fiscales y de los ingresos de derecho soberano, y el comando de las fuerzas

\footnotetext{
${ }^{54}$ Zsolt Trócsányi, Erdély központi kormányzata 1540-1690 [El sistema de gobierno central de Transilvania, 1540-1690], Budapest, Akadémiai, 1980; Zsolt Trócsányi, Habsburg-politika és Habsburg-kormányzat Erdélyben 1690-1740 [La política de los Habsburgo y la administración pública en Transilvania, 1690-1750], Budapest, Akadémiai, 1988.

${ }^{55}$ Ember, op. cit., 17-22.
} 
armadas estacionadas en el territorio del país. Se ocupaba también de los deberes políticos surgidos a lo largo del desarrollo histórico o apenas en proceso de formación (la tributación, las provisiones militares, la agricultura, la industria, el comercio, el control de transportes, la edición de libros, la educación pública, la sanidad pública, la reglamentación de la relación señor-siervo y la supervisión de varias fundaciones).

El Presidente del Consejo de Lugartenencia fue siempre el habitual palatino, sustituido en su ausencia por el Presidente del Tribunal Supremo; según su ley constitutiva, el Consejo inició su funcionamiento con 22 miembros nombrados por el rey, elegidos de "las órdenes de clérigos, magnates y nobles, de todas las partes del país". El Consejo de Lugartenencia funcionó como el poder ejecutivo de Hungría hasta 1848; su influencia ejercida sobre el país entero y sobre una gran variedad de asuntos lo convirtió en el órgano gubernamental más poderoso de la Hungría de los siglos XVIII-XIX.

\section{Bibliografía selecta}

Die Habsburgermonarchie 1620 bis 1740. Leistungen und Grenzen des Absolutismusparadigmas, Hrsg. Petr Mat'a-Thomas Winkelbauer. Stuttgart, Franz Steiner, 2006 (Forschungen zur Geschichte und Kultur des östlichen Mitteleuropa, 24).

FAZEKAS, István: "Die Verwaltungsgeschichte des Königreichs Ungarn und seiner Nebenländer (1526-1848)", Herrschaftsverdichtung, Staatsbildung, Bürokratisierung. Verfassungs-, Verwaltungs- und Behördengeschichte der Frühen Neuzeit, Hrsg. Michael Hochedlinger, Thomas Winkelbauer (Veröffentlichungen des Instituts für Österreichische Geschichtsforschung, 57) Wien-München, Böhlau-Oldenbourg, 2010, 479-502.

Kriegführung und Staatsfinanzen: Die Habsburgermonarchie und das Heilige Römische Reich vom Dreißigjährigen Krieg bis zum Ende des habsburgischen Kaisertums 1740, Hrsg. Peter Rauscher. Münster, Aschendorff, 2010 (Geschichte in der Epoche Karls V., Bd. 10).

PÁLFFY, Géza: The Kingdom of Hungary and the Habsburg Monarchy in the Sixteenth Century [Translated from the Hungarian by Thomas J. and Helen D. DeKornfeld] Boulder, Colorado, Social Science Monographs-Wayne, New Jersey, Center for Hungarian Studies and Publications, Inc.-New York: Distributed by Columbia University Press, 2009 (East European Monographs, DCCXXXV; CHSP Hungarian Studies Series, 18) XVIII, 410 pp. 


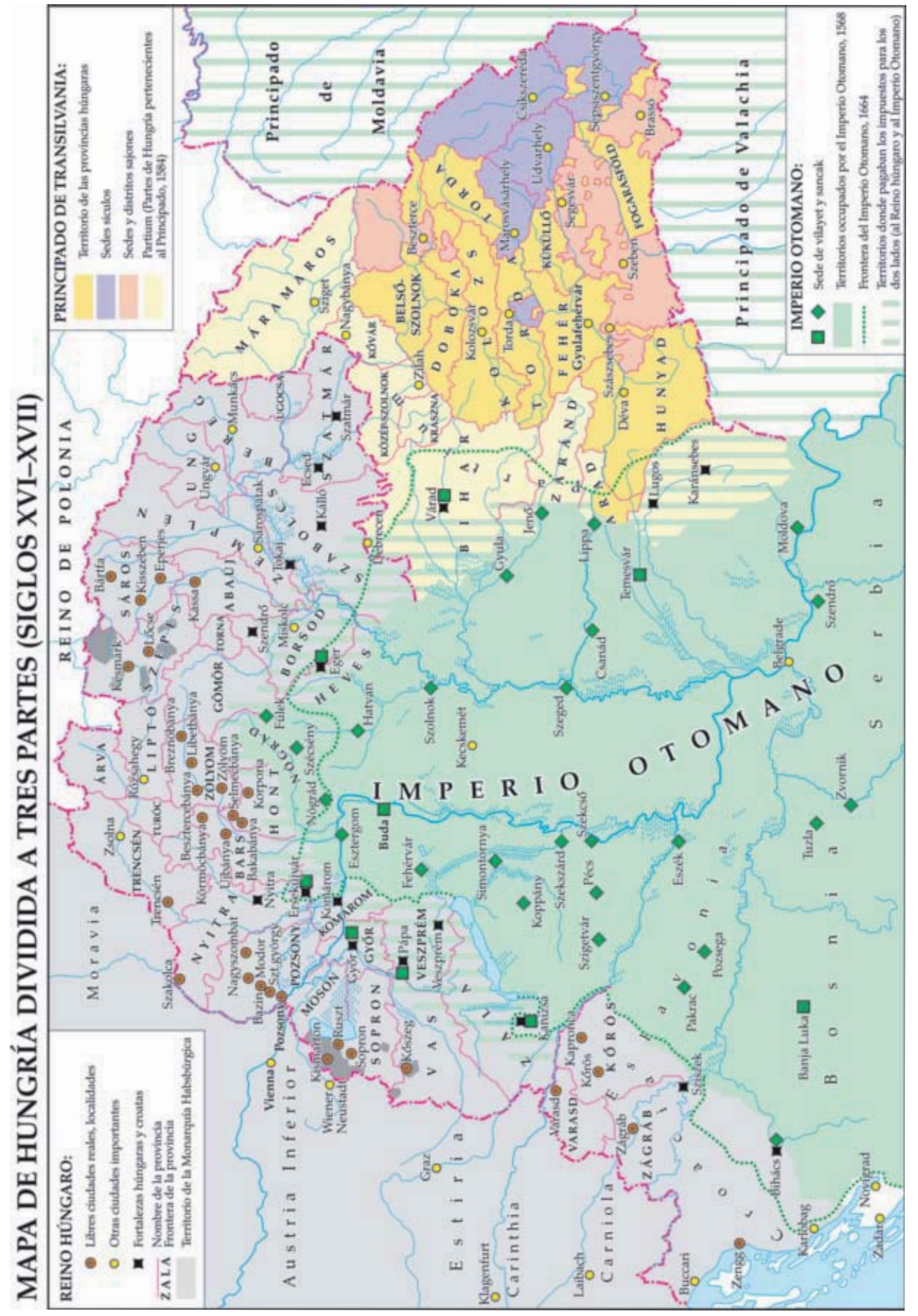

